\title{
Intelligent Maximum Power Tracking Control For a Wind Energy System Based on Magnetic Gear Generator
}

\author{
Kamel Salim Belkhir \\ Department of Electrical Engineering, \\ Faculty of technology, \\ University Ferhat Abbas Setif 1, \\ Setif, Algeria \\ ksbelkhir@univ-setif.dz
}

\begin{abstract}
This paper studies maximum wind power extraction from magnetic gear generator using an artificial neural network for the wind energy system. High speed can be reached with this representation either without mechanical gear or under low wind conditions often found inland. In order to track maximum power, the artificial neural network controller adjusts the outer rotor speed, and thus, inner rotor speed. The proposed system is supported by simulation results.
\end{abstract}

Keywords-artificial neural network; magnetic gear generator; wind power

\section{INTRODUCTION}

Given the rapid development of wind turbine technology, in the future focus will be given on huge offshore single wind turbines, due to their higher wind speed and more space characteristics [1]. Bigger turbines reach higher heights above the ground, where stronger winds blow. This allows them to extract more energy, and to work more efficiently. Using higher-capacity wind turbines reduces the number of turbines needed for a wind farm and results in dramatic reduction of the cost of wind energy [2]. Wind turbines have grown from an average of $700 \mathrm{~kW}$ to over $5 \mathrm{MW}$ during the last decade. Due to reliable and efficient offshore wind energy, several offshore wind projects have been adopted. The offshore applications require lager turbine units, the size of wind turbine is about $7 \mathrm{MW}$ at the present time and the larger turbines of the near future would be about 20MW [3]. This virtual 20MW design is still not apt for manufacturing and is uneconomic. Its weight would be about 880 tones standing on top of a tower, which means that the plan is not feasible. The support structures could not carry such a big generator, the lubrication system and the huge mechanical gearbox elevated up to 153 meters in height $[4,5]$. By removing the mechanical gearbox and the lubrication system, we can reduce the nacelle size and weight. To achieve this goal, we used magnetic gear power-split. The high-torque magnetic gear was invented and demonstrated in 2001 [6]. It uses permanent magnets to transmit torque between an input and output shaft without mechanical contact. The topology and high performance of magnetic gear have been presented in [6] and it has been shown that by using rare-earth magnets, a high torque density can be achieved along with a reduced acoustic noise and vibration, reduced maintenance and improved reliability, precise peak torque transmission capability, and physical isolation between input and output shafts $[7,8]$. The mechanical gearbox is used extensively to increase the rotational speed of wind power generators. It is usually more costly and weights more when a high-speed electrical machine is used along with a gearbox to transform speed and torque. The mechanical gearbox requires lubrication and cooling, while noise, vibration and reliability can be significant issues. The aim of this paper is MPPT control of a $2.5 \mathrm{MW}$ magnetic gear generator, an artificial neural network controller is designed for the MPPT control of this system. The controller adjusts the outer rotor speed, and thus, the inner rotor speed. The effectiveness of the proposed procedure is verified by simulation results.

\section{OPERATING SYSTEM}

The proposed magnetic gear is showed in Figure 1. There are two permanent magnetic rotors and between them there is a ferromagnetic pole-pieces rotor. One of the two permanent magnet rotors is held stationary. The numbers $n_{s}=166, p_{l}=168$ and $p_{h}=5$, present the pole-pieces low-speed ferromagnetic rotor (input rotor), pole-pairs stationary permanent magnet, and pole-poles high-speed permanent magnetic rotor (output rotor) respectively. A wind turbine extracts kinetic energy from the swept area of the blades. The mechanical energy is transferred to the shaft of the input rotor, which is transmitted magnetically from the input rotor to the output rotor. The permanent magnet of the output rotor interacts with the stator windings to produce electromagnetic torque. Thus, the power captured by the wind turbine is transmitted to the grid by the stator winding. The gear ratio of the proposed machine is:

$$
G_{r}=\frac{n_{s}}{p_{h}}
$$

We can see that the speed which needs to be applied to the 
output rotor is independent of the torques of the rotors, and is a function of the applied input speed and gear ratio. The equation of the motions of the magnetic gear is given by [1]:

$$
p_{h} \omega_{h}=n_{s} \omega_{s}
$$

where $\omega_{h}$ and $\omega_{\mathrm{s}}$ are the speed of the output and input rotors respectively. The link between the torques is [1]:

$$
T_{h}=-\frac{1}{G_{r}} T_{S}
$$

It is clear that the torque which needs to be applied to the output rotor is independent of the speeds of the rotors, and is a function of the applied input torque and gear ratio.

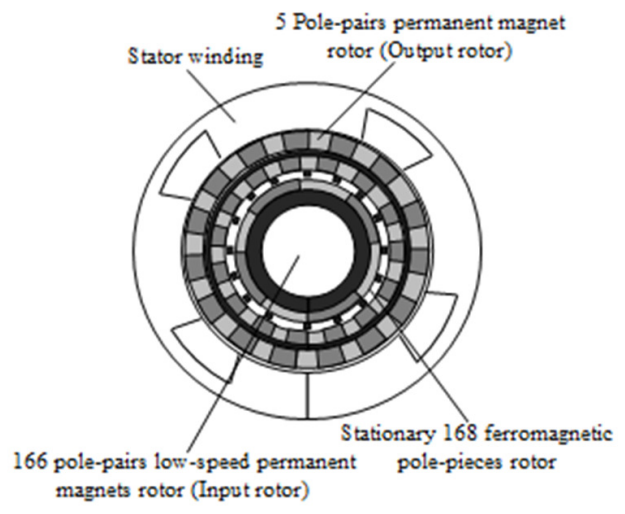

Fig. 1. Radial cross section of magnetic gear generator.

The equations of the rotors motion are given by [1]:

$$
\left\{\begin{array}{c}
J_{s} \frac{d^{2} \theta_{s}}{d t^{2}}=T_{\text {turbine }}-T_{\text {max }} \sin \left(n_{s} \theta_{s}-p_{h} \theta_{h}\right) \\
J_{h} \frac{d^{2} \theta_{h}}{d t^{2}}=T_{e}-T_{\max } \frac{p_{h}}{n_{l}} \sin \left(p_{h} \theta_{h}-n_{p} \theta_{p}\right) \\
T_{e}=\frac{3}{2} p_{h}\left(\varphi_{s d} i_{s q}-\varphi_{s q} i_{s d}\right)
\end{array}\right.
$$

where $\theta_{h}$ and $\theta_{s}$ are the angular position of the output rotor and the input rotor respectively, $\varphi$ is flux linkage, $i$ is the current, $s$ indicate the stator winding, $T_{\text {turbine }}$ is the wind turbine torque, $T_{e}$ is the electromagnetic torque which results from the interaction between the permanent magnets on output rotor and the stator winding, $T_{\max }$ is the maximum torque which can be produced by the magnetic gear and $J_{h}$ and $J_{s}$ are the inertias of the output rotor and the input rotor respectively.

\section{CONTROL STRATEGY OF THE PROPOSED MAGNETIC GEAR GENERATOR}

Figure 2 displays the suggested control topology of the wind power generation system consisting of a magnetic gear generator connected to the grid through a back-to-back converter [9]. It includes two converters connected by a capacitor. The converter connected to the magnetic gear generator is used as a rectifier, while the converter connected to the grid is used as an inverter [15]. To determine the optimal generator speed that ensures maximum energy, a controller should be included that can track the maximum peak regardless of wind speed. Many maximum power point tracking studies have been proposed [10-14]. Since the wind energy system is a nonlinear form, an artificial neural network can be used to solve this problem.

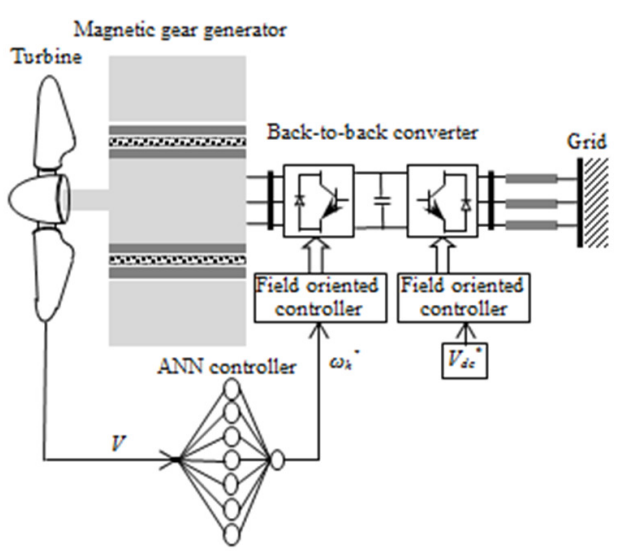

Fig. 2. Magnetic gear generation topology.

\section{A. Magnetic Gear Generator Side Control}

The magnetic gear generator side converter is controlled the input rotor to the reference speed $\omega_{s}{ }^{*}$ using maximum power tracking algorithm to extract maximum power from the wind turbine. A wind turbine extracts kinetic energy from the swept area of the blades, the power transferred to the wind turbine rotor is [17]:

$$
P_{t}=\frac{1}{2} C_{p}(\beta, \alpha) \rho A V^{3}
$$

where $P_{t}$ is the wind turbine power, $C_{p}$ the power coefficient, $\rho$ the air density, $A$ the swept area of rotor, $V$ the wind speed, $\beta$ the blade pitch angle, and $\alpha$ the angle of attack. The tip speed ratio is defined as the ratio between the blade tip speed and the wind speed $V[17]$ :

$$
\lambda=\omega \frac{R}{V}
$$

where $\omega$ is the turbine rotor speed and $R$ the radius of the wind turbine blade.

The stator winding of the magnetic gear generator is modeled in the rotor reference frame $d q$-axes by:

$$
\left\{\begin{array}{l}
V_{s d}=\frac{d \varphi_{s d}}{d t}-R_{s} i_{s d}-\omega_{h} \varphi_{s q} \\
V_{s q}=\frac{d \varphi_{s q}}{d t}-R_{s} i_{s q}+\omega_{h} \varphi_{s d}
\end{array}\right.
$$

where $v$ is the stator voltage and $R$ resistance. The flux linkages are:

$\left\{\begin{array}{l}\varphi_{s d}=L_{s} i_{s d}-\varphi_{P M} \\ \varphi_{s q}=L_{s} i_{s q}\end{array}\right.$

where $\varphi_{P M}$ is the flux of the permanent magnets and $L$ the inductance.

The electromagnetic torque is:

$$
T_{e}=\frac{3}{2} p_{h}\left(\varphi_{s d} i_{s q}-\varphi_{s q} i_{s d}\right)
$$


From (9), due to the cross-related flux terms, it is not easy to control the electromagnetic torque. So, the reference frame $d q$ is chosen in such a way that:

$$
i_{s d}=0 \text { and } i_{s q}=i_{s}
$$

Now, the electromagnetic torque can be simplified into:

$$
T_{e}=\frac{3}{2} p_{\mathrm{h}} \varphi_{P M} i_{s q}
$$

Thus, the electromagnetic torque can be controlled through $i_{s q}$. The $i_{s d}$ and $i_{s q}$ errors can be tuned by a PI controller. The controller is based on two loops, the inner loop is a current controller and the outer loop is a torque controller. From (2), (4), (7), (8) and (11) the general structure of control strategy for magnetic gear generator inverter can be represented by Figure 4.

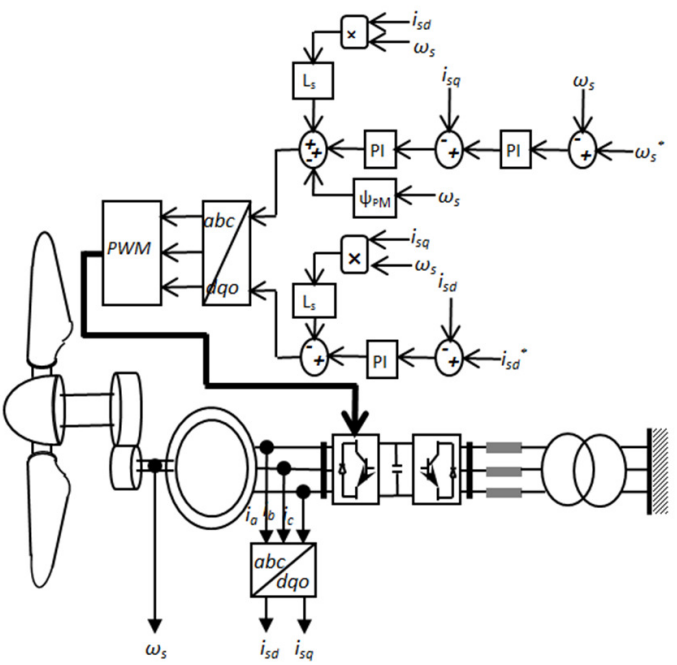

Fig. 3. General structure of magnetic gear generator-side control

\section{B. Artificial Neural Network Based MPPT Control}

The MPPT controller adopts a back-propagation artificial neural network and its structure is multilayer feed-forward network. The study uses the learning method to estimate speed of magnetic gear generator, the scheme of the proposed training is shown in Figure 4. The rpm samples are used as targets to train a 3-layer network, with 1 linear neuron in the input layer, 7 tan-sigmoid neurons in the first hidden layer, and 1 linear neuron in the output layer. The input network parameter wind speed is in $(\mathrm{m} / \mathrm{s})$ and the output network parameter is a speed of magnetic gear (rpm). The training operation is made in a few cycles using 06 input-output patterns.

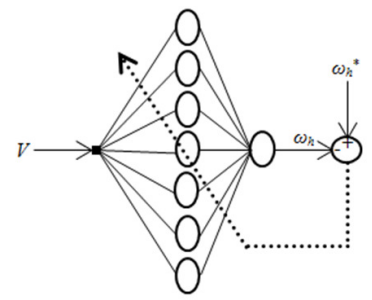

Fig. 4. Training scheme using ANN controller

\section{Grid Side Control}

The grid side inverter controls the active and reactive power flowing between the inverter and the grid [14]. The active and reactive powers produced by the magnetic gear generator are:

$$
\left\{\begin{array}{l}
P=\frac{3}{2}\left(e_{d} i_{d}+e_{q} i_{q}\right) \\
Q=\frac{3}{2}\left(e_{q} i_{d}-e_{d} i_{q}\right)
\end{array}\right.
$$

where $e$ is the voltage at the output inverter and $i$ the line current. To overcome the problem of cross-related voltage terms in (12), the $d q$ reference frame, is chosen in such a way that:

$$
v_{q}^{\prime}=0 \text { and } v_{d}^{\prime}=\left|v^{\prime}\right|
$$

So the active and the reactive power will be proportional to $i_{d}$ and $i_{q}$ respectively:

$$
\left\{\begin{array}{l}
P=\frac{3}{2} e_{d} i_{d} \\
Q=-\frac{3}{2} e_{d} i_{q}
\end{array}\right.
$$

Now, the active power can be controlled via $i_{d}$ and the reactive power can be controlled via $i_{q}$. The $i_{q}$ is usually set to zero in order to achieved unit power factor [15]. The voltage equations of grid side inverter can be defined by:

$$
\left\{\begin{array}{l}
e_{d}=R_{T} i_{d}+L_{T} \frac{d i_{d}}{d t}-\omega L_{T} i_{q}+v_{d}^{\prime} \\
e_{q}=R_{T} i_{q}+L_{T} \frac{d i_{q}}{d t}-\omega L_{T} i_{d}
\end{array}\right.
$$

where $e$ is the voltage at the output inverter, $R_{T}$ and $L_{T}$ are the overall resistance and inductance of the grid-side converter and $\omega$ is the electrical angular velocity. From (14) and (15), the general structure of control strategy for grid-side inverter can be represented by Figure 5. The inverter is based on two loops, the inner loop is a current controller, and the outer loop is a dclink and reactive power controllers.

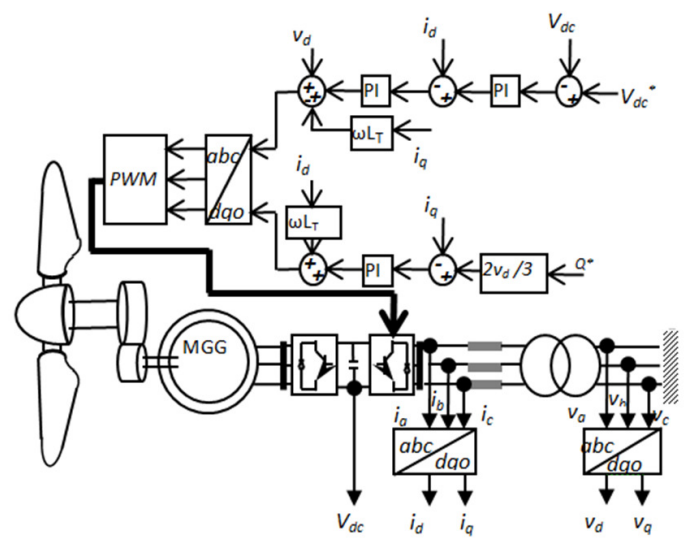

Fig. 5. General structure of grid side control

\section{SimULATION RESUlTS}

To evaluate the high performance MPPT controller, simulations were conducted with variable wind speed. Table I shows the parameters of the magnetic gear generator. The wind speed variation is shown in Figure 6. The magnetic gear side 
converter is controlled by the artificial neural network controller to maintain the output rotor to the rated speed to collect maximum power. As shown in Figures 7 and 9, there is a good agreement between the reference values of the estimated high speed rotor and of output rotor speed. As revealed in Figures 6 and 11, when the wind speed increases, the input mechanical power also increases and thus the electrical power produced by the generator increases.

TABLE I. SYSTEM PARAMETERS

\begin{tabular}{|c|c|}
\hline \multicolumn{2}{|c|}{ Magnetic gear generator } \\
\hline Rated power & $2.5 \mathrm{MW}$ \\
\hline Rated voltage & $900 \mathrm{~V}$ \\
\hline Winding resistor & $0.001 \Omega$ \\
\hline Inductance $\boldsymbol{L}_{\boldsymbol{d}}$ & $0.0007 \mathrm{H}$ \\
\hline Inductance $\boldsymbol{L}_{\boldsymbol{q}}$ & $0.0007 \mathrm{H}$ \\
\hline Number of pole-pairs inner rotor & 166 \\
\hline Number of pole-pairs outer rotor & 5 \\
\hline \multicolumn{2}{|c|}{ Transmission line } \\
\hline Resistance & $0.01273 \Omega / \mathrm{KM}$ \\
\hline Inductance & $0.0009337 \mathrm{H} / \mathrm{KM}$ \\
\hline Distance & $7 \mathrm{Km}$ \\
\hline
\end{tabular}

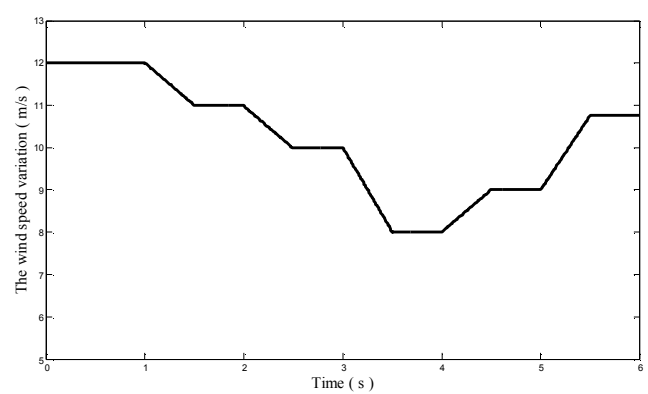

Fig. 6. Wind speed variation vs time

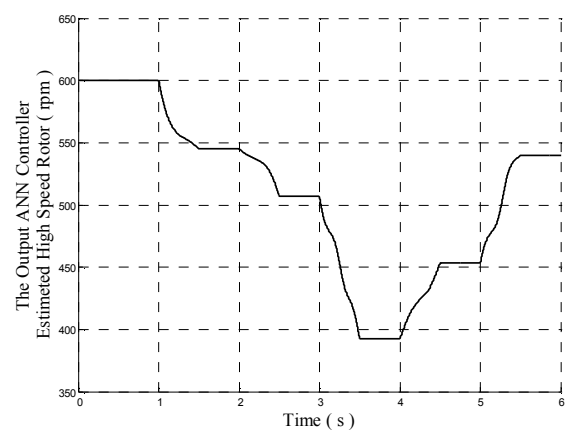

Fig. 7. The output of the artificial neural network controller

Figures 8 and 9 show the output and input rotors' variation. For example, we can see that, from $18 \mathrm{rpm}$ of the inner rotor and without mechanical gear, the output rotor reached $600 \mathrm{rpm}$. That means that even under low wind conditions often found inland, and without mechanical gear, high speed can be reached using magnetic gear generator. The performance of the proposed artificial neural network controller is compared with a fixed rated speed in Figures 11 and 12. The artificial neural network controller provides superior performance, as it derives maximum possible power from the wind at different wind speeds.

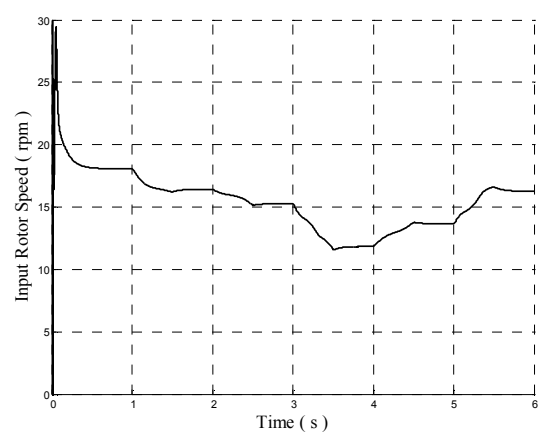

Fig. 8. Speed of the input rotor

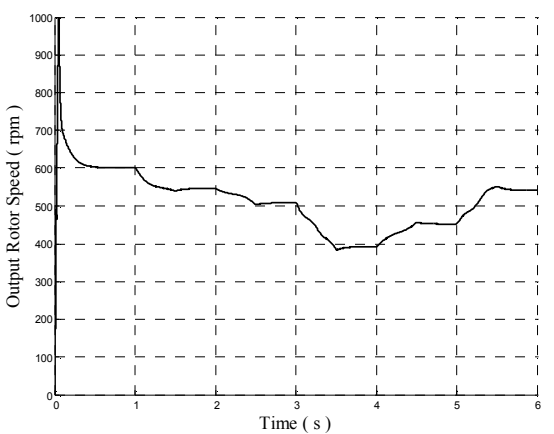

Fig. 9. Speed of the output rotor

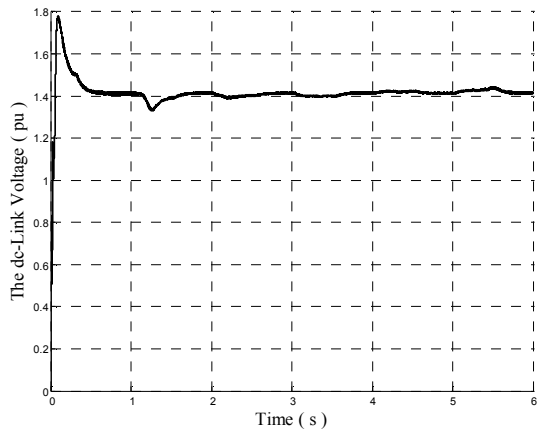

Fig. 10. dc-link voltage

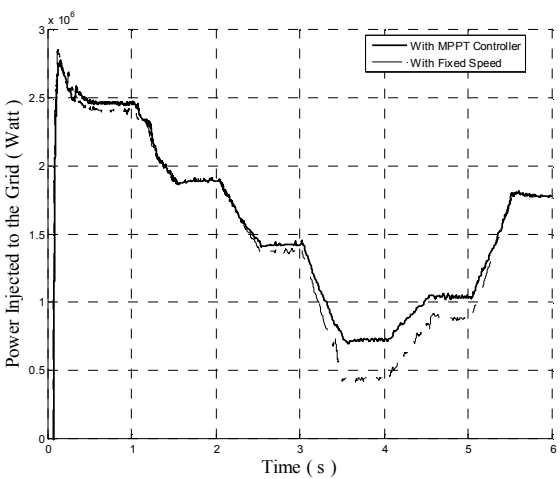

Fig. 11. Power injected to the grid 


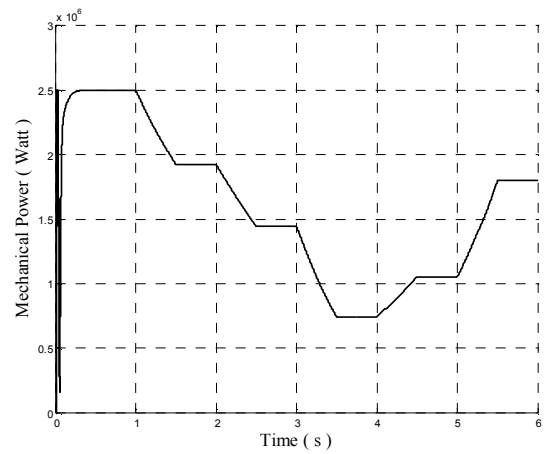

Fig. 12. Mechanical turbine power

To realize the feasibility of the grid side controller, Figure 10 presents the dc link voltage variation. The controller gives good agreement between the actual and reference values of the dc link voltage thus the actual dc voltage is almost constant over the whole period.

\section{CONCLUSION}

In this paper, an artificial neural network based MPPT controller method applied to a 2.5 magnetic gear generator was proposed. It was shown that with low wind conditions, high speed variation can be achieved using the proposed magnetic gear generator. The proposed controller has fast dynamic characteristics, regardless of the changes in wind speed. Simulation was performed on a $2.5 \mathrm{MW}$ magnetic gear generator and the results confirm the benefits of the proposed topology.

\section{REFERENCES}

[1] V. Markovitz, "Sizing Up Wind Energy: Bigger Means Greener Study Says", National Geographic News, available at: https://news. nationalgeographic.com/news/energy/2012/07/120720-bigger-windturbines-greener-study-says/, 2012

[2] J. Helsen, F. Vanhollebeke, D. Vandepitte, W. Desmet, "Some trends and challenges in wind turbine upscaling", in: Proceedings of ISMA International Conference on Noise and Vibration, Leuven, pp. 43454359, Katholieke Universiteit Leuven, 2012

[3] P. Dvorak, "Britannia breaks the 9 MW barrier", Windpower Engineering and Development, available at: https://www. windpowerengineering.com/projects/britannia-breaks-the-9-mw-barrier, 2010

[4] L. R. Martin, "Wind energy-the facts: A guide to the technology, economics, and future of wind power", Journal of Cleaner Production, Vol. 18, No. 10, pp. 1122-1123, 2010

[5] J. Beurskens, "Achieving the $20 \mathrm{MW}$ wind turbine", available at: https:// www.renewableenergyworld.com/articles/print/special-supplementwind-technology/volume-1/issue-3/wind-power/achieving-the-20-mwwind-turbine.html, 2011

[6] K. Atallah, D. Howe, "A novel high-performance magnetic gear”, IEEE Transactions On Magnetics, Vol. 37, No. 4, pp. 2844-2846, 2001

[7] K. Atallah, S. D. Calverley, D. Howe, "Design, analysis and realisation of a high-performance magnetic gear", IEE Proceedings-Electric Power Applications, Vol. 151, No. 2, pp.135-143, 2004

[8] K. Atallah, J. Rens, S. Mezani, D. Howe, "A novel "Pseudo" directdrive Brushless permanent magnet machine", IEEE Transactions on Magnetics, Vol. 44, No. 11, pp.4349-4352, 2008

[9] H. Camblong, I. M. de Alegria, M. Rodriguez, G. Abad, "Experimental evaluation of wind turbines maximum power point tracking controllers",
Energy Conversion and Management, Vol. 47, No. 18-19, pp. 28462858, 2006

[10] C. Y. Lee, Y. X. Shen, J. C. Cheng, Y. Y. Li, C. W. Chang, "Neural networks and particle swarm optimization based MPPT for small wind power generator", World Academy of Science, Engineering and Technology, Vol. 3, No. 12, pp. 2222-2228, 2009

[11] C. Y. Lee, P. H. Chen, Y. X. Shen, "Maximum power point tracking (MPPT) system of small wind power generator using RBFNN approach", Expert Systems with Applications, Vol. 38, No. 10, pp. 12058-12065, 2011

[12] I. Munteanu, A. I. Bratcu, E. Ceanga, "Wind turbulence used as searching signal for MPPT in variable-speed wind energy conversion systems", Renewable Energy, Vol. 34, No. 1, pp. 322-327, 2009

[13] W. M. Lin, C. M. Hong, "Intelligent approach to maximum power point tracking control strategy for variable-speed wind turbine generation system”, Energy, Vol. 35, No. 6, pp. 2440-2447, 2010

[14] R. Kot, M. Rolak, M. Malinowski, "Comparison of maximum peak power tracking algorithms for a small wind turbine", Mathematics and Computers in Simulation, Vol. 91, pp. 29-40, 2013

[15] Y. Y. Hong, S. D. Lu, C. S. Chiou, "MPPT for PM wind generator using gradient approximation", Energy Conversion and Management, Vol. 50, No. 1, pp. 82-89, 2009

[16] S. M. Muyeen, A. A. Durra, J. Tamura, "Variable speed wind turbine generator system with current controlled voltage source inverter", Energy Conversion and Management, Vol. 52, pp. 2688-2694, 2011

[17] Z. Qi, E. Lin, "Integrated power control for small wind power system", Journal of Power Sources, Vol. 217, pp. 322-328, 2012 